\title{
Closeness to social network and COVID-19
}

\author{
Rujittika Mungmunpuntipantip ${ }^{1} \cdot$ Viroj Wiwanitkit $^{2}$
}

Received: 12 July 2021 / Accepted: 8 August 2021 / Published online: 23 August 2021

(c) The Author(s), under exclusive licence to Springer Nature Switzerland AG 2021

\section{Dear Editor,}

We would like to share ideas on "Closeness to friends explains age differences in positive emotional experience during the lockdown period of COVID-19 pandemic [1]." Cavallini et al. concluded that "our findings reinforce the link between perceived .... adults to increase the closeness to their social network [1]." Closeness to social network is necessary for positive emotion. However, it might not be possible in some areas. In our areas in Asia, where the infrastructure is limited, it is usually difficult to promote closeness of social network. In addition, we have to control the use of social network. Too much use can cause problem. Addiction to social network might occur, and it can cause negative effect such as anxiety [2], and information overload [3].

\section{Declarations}

Conflict of interest The authors declare that they have no conflict of interests.

\section{References}

1. Cavallini E, Rosi A, van Vugt FT et al (2021) Closeness to friends explains age differences in positive emotional experience during the lockdown period of COVID-19 pandemic. Aging Clin Exp Res. https://doi.org/10.1007/s40520-021-01927-7

2. Ruiz MJ, Sáez G, Villanueva-Moya L et al (2021) Adolescent sexting: the role of body shame, social physique anxiety, and social networking site addiction. Cyberpsychol Behav Soc Netw. https:// doi.org/10.1089/cyber.2020.0719

3. Bala R, Srivastava A, Ningthoujam GD et al (2021) An observational study in Manipur State, India on preventive behavior influenced by social media during the COVID-19 pandemic mediated by cyberchondria and information overload. J Prev Med Public Health 54:22-30

Publisher's Note Springer Nature remains neutral with regard to jurisdictional claims in published maps and institutional affiliations.

Rujittika Mungmunpuntipantip

rujittika@gmail.com

1 Private Academic Consultant, Bangkok, Thailand

2 Dr DY Patil University, Pune, India 